\title{
Using Range Condition Assessment to Optimize Wildlife Stocking in Tindress Wildlife Sanctuary, Nakuru District, Kenya
}

\author{
Shadrack M. Muya, ${ }^{1}$ Able M. Kamweya, ${ }^{2}$ Anne W. T. Muigai, ${ }^{3}$ Apollo Kariuki, ${ }^{4}$ \\ and Shadrack M. Ngene \\ Authors are ${ }^{1}$ Lecturer in Ecology and Conservation Genetics and ${ }^{2}$ Senior Lecturer in Ecology, Department of Zoology, and ${ }^{3}$ Professor of Genetics, \\ Department of Botany, Jomo Kenyatta University of Agriculture and Technology, Nairobi, Kenya; and ${ }^{4}$ Senior Resource Planner and ${ }^{5}$ Elephant \\ Programme Coordinator, Department of Biodiversity Research and Monitoring, Kenya Wildlife Service, Nairobi, Kenya.
}

\begin{abstract}
Over $70 \%$ of Kenya's wildlife resources occur outside protected areas, in areas where land use practices do not necessarily conform to wildlife conservation standards. Ensuring that land use practices in these areas accommodate wildlife conservation is vital in effectively conserving wildlife in this country. Tindress Farm in Rift Valley offers a good example of a place where economic activities and wildlife conservation can work harmoniously. The farm has set up a 320-ha wildlife sanctuary in the hilly parts of the property to provide a haven for wildlife displaced by human settlements in the surrounding environs. The Tindress Farm management needed to know the diversity and optimum number of wildlife species that the sanctuary could accommodate. This study set out to 1) outline a set of models for objectively calculating wildlife stocking levels and 2) demonstrate the practical use of these models in estimating optimum stocking levels for a specific wildlife sanctuary. After comparing models using forage inventory methods models and utilization-based methods (UM), we opted to use UM models because of their focus on ecological energetics. This study established that the range condition in Tindress Wildlife Sanctuary varied from poor to good (29-69\%) and recommended a total stocking density of 158.9 grazer units and 201.4 browser units shared out by the various herbivore species. These estimates remain a best-case scenario. The effects of rainfall, range condition, and condition of the animals should be monitored continuously to allow for adjustments through active adaptive management.
\end{abstract}

Key words: browsing unit, utilization-based models, wildlife utilization, wildlife carrying capacity

\section{INTRODUCTION}

Over $70 \%$ of Kenya's wildlife resources are found outside national parks (Ngunjiri 1997), in areas where the core economic activities are not necessarily in conformance with wildlife conservation standards. There are several threats to loss of this wildlife, especially from destruction of habitat and poaching (Kamweya et al. 2012). Such losses would deal a devastating blow to conservation efforts in Kenya. Apparently, the wildlife-based tourism industry would collapse and Kenya's Vision $2030^{1}$ would not be realized. Poaching, encroachment on wildlife habitats by settlements, farms, charcoal burners, logging, and hunting are the major threats to wildlife survival in these lands, since most of them lack structured security services (Jambiya et al. 2007). Competition for resources between human beings and livestock on one hand and wild animals on the other is exacerbating the threat. Transmission of contagious diseases such as rinderpest between the wildlife and livestock is another major factor that could lead to the decimation of the wildlife populations. Landowners carry the burden of hosting wild animals on their land by maintaining them on the land

\footnotetext{
${ }^{1}$ http://www.vision2030.go.ke.

We appreciate the management of Tindress Farm, especially Mr Suguma and Mansukh Patel, for funding this study.

Correspondence: Dr Shadrack Muya, Faculty of Science, Jomo Kenyatta University of Agriculture and Technology, Nairobi, Kenya. Email: smuvui@gmail.com
}

Manuscript received 25 June 2012; manuscript accepted 26 February 2013.

(c) 2013 The Society for Range Management with very few benefits, if any (Watson et al. 2010). This calls for active management of wildlife populations outside formal wildlife protected areas in order to enhance benefits and/or reduce costs incurred by landowners. Land production systems are expensive and must be economically viable in order be sustained. Landowners have to choose the most viable production systems. Returns from wildlife conservation must outperform a myriad of other land uses for landowners to adopt wildlife conservation as a preferred land use option (Watson et al. 2010). Appropriate habitat management practices are crucial in commercial use of free-ranging wildlife populations. In these cases, the managers must understand and apply these procedures accurately (Watson et al. 2010).

The management of Tindress Farm set up a wildlife sanctuary in the hilly parts of the farm, which they considered to be an ideal area to undertake wildlife conservation because of its pristine state. For Kenya Wildlife Service to permit Tindress Farm to keep wildlife in the sanctuary, the farm managers were required to develop a management plan with a clear outline of activities that would take place in the sanctuary and its carrying capacity of various wildlife species. Obtaining estimates of stocking rates/carrying capacities of the sanctuary (and the range at large) is also important because of the potential adverse effects of underutilization of the range. Overutilization can lead to bush encroachment and overgrazing, a primary cause of soil erosion and reduced productivity. Effective management and conservation of biological resources such as wildlife require that mangers know the population sizes of the species mix they contain in areas of their ranches or nature reserves. There is a dearth of 
information that can be used as a management tool and is readily available to ranchers, farmers, or wildlife managers, particularly in most African ecosystems.

In eastern Africa, there is no standard approach in place to calculate wildlife carrying capacity that recognizes the different requirements of grazers, browsers, and mixed feeders as well as varying metabolic demands of wildlife species. In 1960s and 1970s, several ecologists suggested some models for estimating herbivore carrying capacities for in East African habitats. For instance, estimation of consumption has several approaches based on its relationship with animal body weight (Pratt et al. 1977; Delany and Happold 1979). However, the estimates were inconsistent and varied widely due to variations in environmental factors such as climate, soils, and fire. This study addresses an emerging need for an objective, repeatable, and easily applied means of calculating wildlife carrying capacity.

\section{Previous Studies on Carrying Capacity and Stocking Levels}

The concept of carrying capacity has been used widely and diversely in natural resource management (Scarnecchia 1990). It has its origin in livestock farming, where it was developed and defined by agriculturalists as the number of animals (grazing livestock thus grazing capacity) that an area can support without degradation of plants or soil resources (Dhondt 1988; Holechek et al. 1989).

The Society for Range Management (1989) defined carrying capacity as "the maximum stocking rate possible which is consistent with maintaining or improving vegetation or related resources." Thus the term carrying capacity represents the maximum rate or level (Forrester 1961) that could be sustained or supported by specified level of resources. Stocking level is defined as the optimum number of individuals or units that specified vegetation or other resources could sustain or support to achieve specific management objectives, within specified management options (Scarnecchia 1990); thus carrying capacity is not an optimum number, but maximum one. If wildlife stocking level is maximized to describe wildlife carrying capacity, then wildlife carrying capacity is defined as the maximum wildlife stocking level to achieve specific objectives within specified management options (Bothma et al. 2006).

\section{Models for Calculating Wildlife Stocking Levels}

The methods used in this study have been extensively used in South Africa. For example, Peel et al. (1994) evaluated the concept of grazer and browser animal units for African savannah areas and tabulated the values for both domestic and wildlife species. In 1986, Smit (1996) developed a method for estimating useful biomass from canopy (BECVOL), an approach that was revolutionary in estimating browsing capacity. Dekker (1997) calculated the stocking rates for game ranches in Mopani Veld using substitution ratios.

Van Rooyen (2002b) in a symposium on game ranch planning and management held in Onderstepoort, South Africa, demonstrated the use of vegetation (veld) condition assessment in determining optimum numbers while stocking a game ranch. Bothma et al. (2006) used diet and plant resources to set wildlife stocking densities in Mopane Ranch in the Limpopo province of northern South Africa. The ranch was established in 2000 on land that was previously managed for cattle ranching. Due to the change in land use from ranching to wildlife conservation, there was a need to determine potential stocking densities for purposes of planning. In Kenya, very little has been done on modeling of wildlife stocking levels. The only outstanding contribution was by Georgiadis et al. (2003); a model was developed for calculating the carrying capacity for zebras in the Laikipia district. In the model, the only driver considered was rainfall.

In this study, we reviewed the various methods used in calculating livestock stocking levels. We established that the most common models available are based on either forage inventory methods (FIMs) or utilization-based methods (UMs). The premise of FIMs is that certain minimum levels of dry matter of primary forage plant species (key plant species) should always be present to maintain the soil quality, forage plant vigor, livestock diet quality, and general wildlife habitat (Holechek 1988). The minimum dry matter levels indicate the highest average degree of use the primary forage species can sustain without loss of productivity. In addition to the keyplant concept, FIMs also apply the key-area concept; no range is uniformly utilized because of the clumped pattern of resource distribution in nature. Even under light grazing intensities, areas around watering points, salt grounds, valley bottoms, and driveways will often be heavily foraged upon. These preferred areas are referred to as "sacrifice areas" because setting stocking rates for proper use of these areas will result in underuse of the bulk of the pasture (Holechek 1988). A major objective of specialized grazing systems is to minimize the size of these sacrifice areas and provide them with periodic opportunity for recovery (Holechek 1983). The success of range management practices within a pasture is usually judged by the response of the key plant species on the key area. FIM models require information on average daily forage intake by different animal species. This is measured as a percentage of animals' body weight per day in dry matter. The data are averaged across periods when forage is dormant and when it is actively growing (Holechek 1988). A stocking level can be calculated once information is obtained on average standing crop of grazeable forage, total area under grazeable pasture, level of grazing intensity the pasture can sustain, and average mass of the animals to be grazed. The downside of FIM models is that they lack information on browsers and are therefore difficult to implement in multiobjective feeding setups occurring in wildlife conservation systems.

The basis of UM models is ecological energetics, whereby it is possible to develop equivalence ratios of different animal species that can be expressed in common animal units. The animal units stocked over some time (the stocking level) (AUM $\cdot \mathrm{ha}^{-1}$ ) are then matched to an estimated carrying capacity (Scarnecchia 1990). This makes the UM models easier to modify and implement in African savannah ecosystems than FIMs. It is important to note that currently no standardized approach is in place in eastern Africa to calculate wildlife carrying capacity, given the different requirements of grazers, browsers, and mixed feeders as well as varying metabolic demand between wildlife species. This paper addresses a clear and emerging need for an objective, repeatable, and easily applied means of calculating wildlife carrying capacity. Earlier efforts to determine carrying capacity for browsing wildlife populations were based on comparisons between the metabolic 
energy requirements for an adult steer, herein referred to as one large stock unit (LSU), primarily a grazer (Meissner 1982; Botha 1999) and any other species of interest. The LSU was the standard unit for measuring stocking levels in terms of the number of LSUs a hectare of land can support without further deterioration.

Among the many UM models available, we adopted a recently published approach in determining wildlife stocking levels that advocates use of herbivore diet and plant resources available in a given habitat as the key factors in determining wildlife stocking levels in African savannas (Bothma et al. 2006). This study considers this approach to be more useful than previous methods that relied solely on carrying capacity as defined by agriculturists, as it incorporates both grazing and browsing conditions of a range. These two factors determine the grazing units (GU) and browsing units (BU) available for sharing by different bovids in a particular ranch (or that can be put in a specific ranch) in order to delineate stocking densities (Bothma et al. 2006).

Definition of Grazing Capacity. In wildlife studies, grazing capacity reflects the potential of ecological production of the grazeable portion of a homogeneous unit of vegetation. It represents the area of land (in hectares) required to maintain a single GU over an extended number of years without deterioration of the vegetation or the soil. A male blue wildebeest (Connochaetes taurinus) with a mass of $180 \mathrm{~kg}$ is commonly taken as $1 \mathrm{GU}$ because C. taurinus is a large herbivore with a diet primarily based on grazing (Bothma et al. 2006). The grazing capacity for wildlife is expressed as $\mathrm{GU} \cdot 100 \mathrm{ha}^{-1}$.

Definition of Browsing Capacity. Similarly, browsing capacity reflects the potential of ecological production of the browseable portion of a homogeneous unit of vegetation and represents the area of land (in hectares) required to maintain a single BU over an extended number of years without deterioration of the vegetation or soil quality. A greater kudu (Tragelaphus strepsiceros) with a mass of $140 \mathrm{~kg}$ is commonly taken as 1 BU in South Africa because it is an abundant large herbivore with a diet primarily based on browsing. The browsing capacity for wildlife is expressed as BU $100 \mathrm{ha}^{-1}$.

In essence, the ecological grazing and browsing capacity for herbivores is the maximum number of grazers and browsers that a given area of land can sustain, based on the biophysical resources of the area. Together they form the ecological capacity of the habitat to support wild herbivores (Bothma 2002). Proposed stocking densities are seldom as high as the ecological grazing and browsing capacities. For maximum wildlife production in a sanctuary, an economic grazing or browsing capacity is therefore usually set at $70-80 \%$ of the ecological grazing or browsing capacity (Van Rooyen 2002a, $2002 \mathrm{~b}$ ) so as to have optimum economic return.

In light of the foregoing, the goal to establish wildlife stocking levels (or carrying capacity) of Tindress Wildlife Sanctuary (TWS) for appropriate management and use of wildlife was achieved by first outlining a set of models that have been used previously to calculate stocking level (carrying capacity) with the view of evaluating their appropriateness for use in savannah ecosystem and, secondly, practically demonstrating how the models in our opinion were most applicable

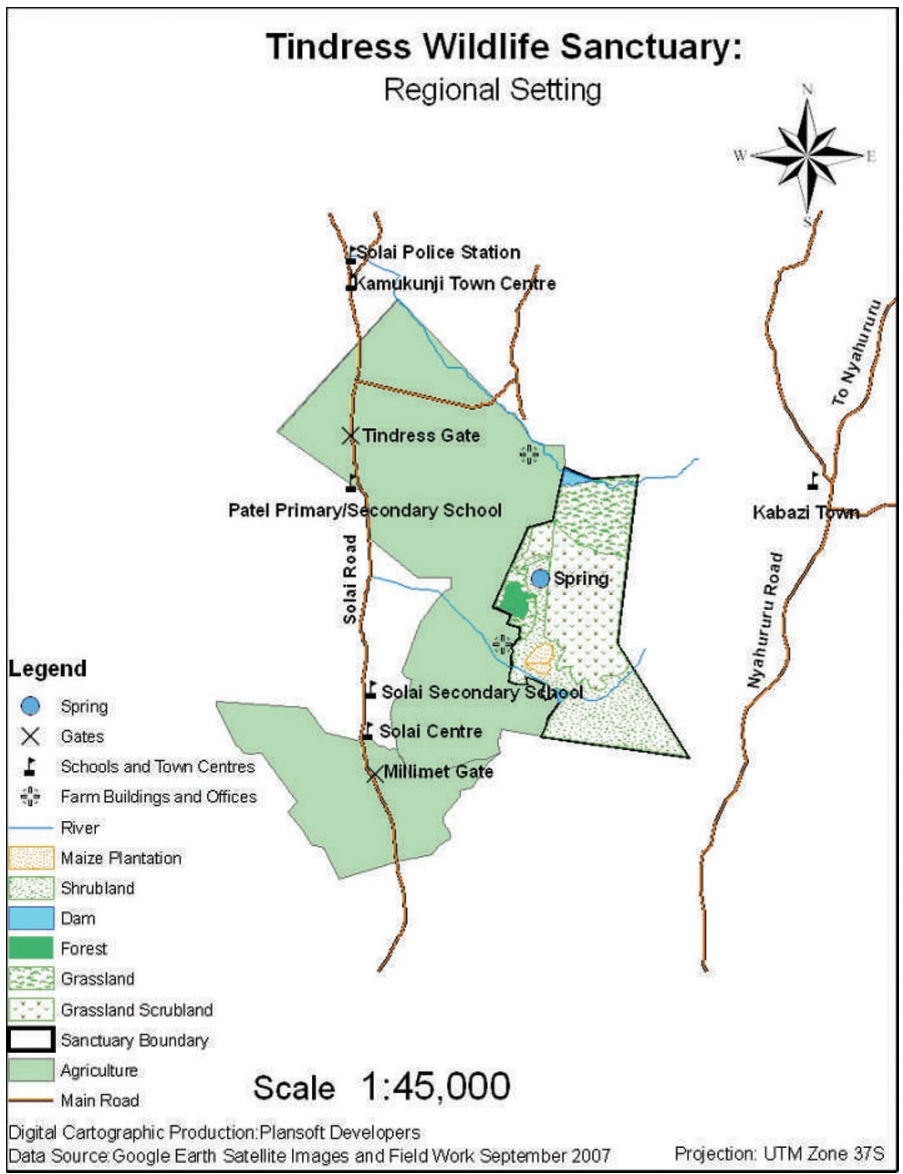

Figure 1. A location map of Tindress Wildlife Sanctuary in relation to its location in Kenya.

for a place like TWS, including data collection methods, analysis, and interpretation in order to make sound decisions on appropriate wildlife stocking levels for TWS.

\section{MATERIALS AND METHODS}

\section{Study Area}

TWS is a small conservation area measuring approximately 320 ha located on Tindress Farm about $35 \mathrm{~km}$ from Nakuru town, along the Nakuru-Solai road (Fig. 1). The farm lies between lat $04^{\circ} 42^{\prime} \mathrm{S}$ and lat $05^{\circ} 01^{\prime} \mathrm{S}$ and long $36^{\circ} 09^{\prime} \mathrm{E}$ and long $36^{\circ} 08^{\prime} \mathrm{E}$, on the slopes of the Solai hills fringing the greater Subukia escarpment on the westerly direction. The main farming activities are floriculture, coffee, and dairy farming.

The sanctuary's physical features include undulating gravel hills, rocky outcrops, three seasonal streams, a spring, and several valley bottoms. The land slopes on an east-westerly direction and provides good soil drainage. The soils covering the area are mainly Latosol and Planosol (KSS 1982). The altitude rises from $1948 \mathrm{~m}$ above the sea level at the valley bottoms to $2013 \mathrm{~m}$ above the sea level at the highest hilltop. The rainy season extends from April to December, with about $85 \%$ of the mean annual rainfall occurring during these 


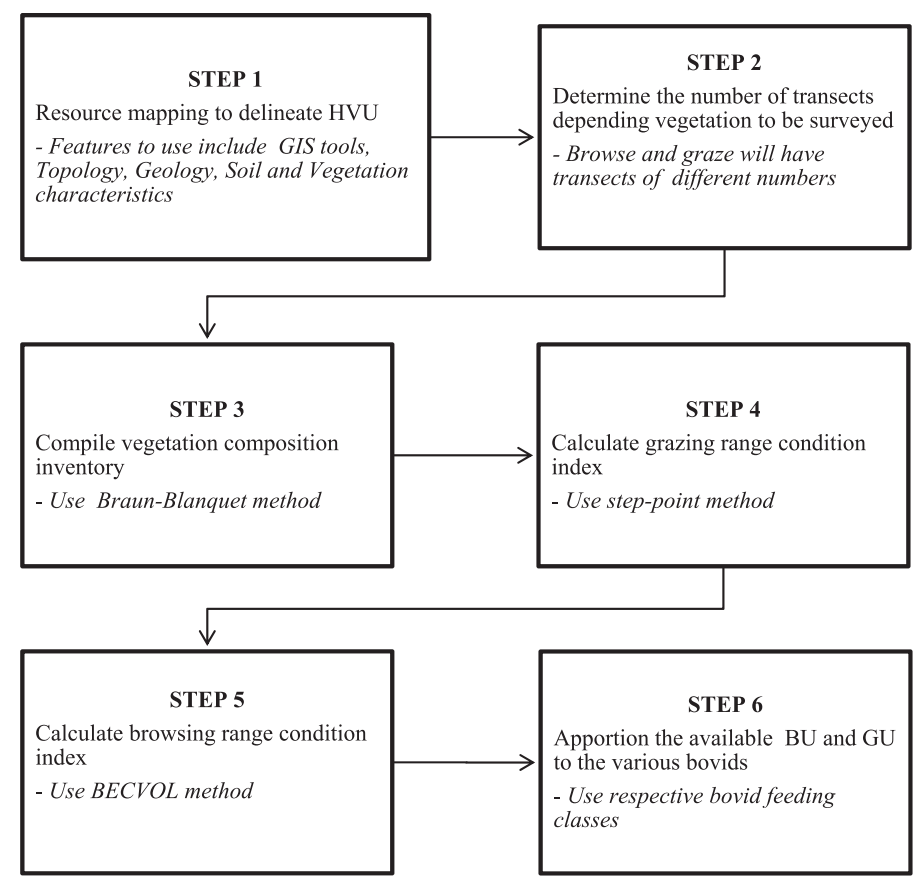

Figure 2. A flow diagram of the steps to follow in calculating wildlife stocking level for a specific conservancy.

months. The 20-yr mean annual rainfall was $1133 \mathrm{~mm}$ with a wide fluctuation in rainfall amounts. Fire emerged as an additional key environmental factor in this area, as it influences abundance and quality of plant resources in space and time. The mean annual ambient temperature was $15.4^{\circ} \mathrm{C}$, ranging between $6.4^{\circ} \mathrm{C}$ and $24.7^{\circ} \mathrm{C}$.

\section{Steps for Calculating Stocking Level}

Determination of stocking level using UM models focuses on evaluating total energy available in a given habitat that is then shared out through substitution ratios. These methods have been developed by several researchers, including Peel et al. (1994), Dekker (1997), Holechek (1988), and Scarnecchia (1990), and modified by Bothma et al. (2006). The procedure is systematic and involves six steps (Fig. 2). Step one involves resource mapping to delineate the conservation area into homogeneous vegetation units (HVU). Step two is concerned with determination of the number of transects in each HVU. Transects should cover at least $30 \%$ of the HVU's total area. Step three focuses on species composition inventory. This is done within transects delineated in step two. Steps four and five involve assessment of browsing and grazing conditions, respectively. Finally, step six deals with calculation of the BUs and GUs and apportioning them to animals appropriate to each habitat. For this purpose, we categorized the large herbivores into four feeding classes (Bothma et al. 2004, 2006):

1) low-selective grazers: these animals have wide mouths and $>80 \%$ of their diet is grass,

2) high-selective grazers: these animals have narrow mouths and $>70 \%$ of their diet is grass,

3) mixed feeders that browse and graze: these animals use from $>30-70 \%$ grass or browse,
4) browsers: these animals eat $>y 80 \%$ wild fruits and browse.

\section{Vegetation Composition Inventory}

We stratified the sanctuary into three homogeneous physiographic vegetation units on the basis of topography (hilltops, slopes, and riverine/valley bottoms), geology, soil, vegetation characteristics, and land types. We conducted a detailed biophysical resource inventory in each HVU. Data on plant species composition were gathered using the Braun-Blanquet method (Kent and Coker 1995) and involved recording the cover of each species in plots of $10 \times 20 \mathrm{~m}$ within each of the different homogeneous physiographic vegetation units. We used vegetation phytosociological tables (MEGATAB 1996; TURBOVEG 1996) to classify the different plant communities into specific phytosociological categories. We determined the surface area occupied by each plant community for the mapped units. The plant communities present were an indicator of the varied wildlife management units available in the sanctuary with each being characterized by its own biophysical diversity and ecological capacity to support wild herbivores.

\section{Assessment of Graze Condition}

We calculated the index of the grazing range condition by using a modified version of the veld-condition index method (Vorster 1982; Danckwertz 1989b). We classified the grasses and forbs into five ecological categories, based on their grazing value, primary production, and palatability following the works of Tainton (1999), Van Oudtshoorn (1999), and Bothma et al. (2006):

Class 1: palatable tufted or stoloniferous grass species with a high productivity and high grazing value;

Class 2: tufted, perennial grass species with an intermediate productivity and moderate grazing value;

Class 3: tufted, tall, perennial grass species with a high productivity but a low grazing value;

Class 4: generally unpalatable, annual and perennial, tufted or stoloniferous grass species with an intermediate productivity and a low grazing value; and

Class 5: unpalatable, annual grass and forb species with a low productivity and low grazing value.

We calculated a range-condition score for each plant community based on a number of 200 step-point surveys at different sites within each plant community (Mentis 1981). We delineated a $30 \times 30 \mathrm{~m}$ area and systematically paced in the said area (each foot was placed in front of each other with the toe touching the foot heel), and at every second step we recorded the grass or forbs nearest to the tip of the foot until a sample of 200 step-points was obtained. If no herbaceous plant occurred within a radius of $0.5 \mathrm{~m}$ of the step-point, we scored this as bare soil. We classified all nongrass herbs collectively as forbs. The percentage of frequency of each grass species and forb was calculated per plant community. We calculated the contribution of each ecological class (1-5 above) to the range-condition score by adding the percentage of frequencies of all the individual species that fell within a given ecological class. We then multiplied the total percentage of contribution of each ecological class by a weighted constant for each class, which reflected its grazing value, palatability, and productivity in phytomass. These weighted constants were 10 for Class 1,7 for 
Class 2, 5 for Class 3, 4 for Class 4, 1 for Class 5, and 0 for bare soil (Tainton 1999).

The sum of all the multiplied grazing values represented the range-condition score for the HVU. Theoretically, the maximum range-condition score for any site was 1000 . This was obtained when all $(100 \%)$ the recorded plant species in a given plant community were classified as belonging to Class 1 , with a weighted grazing value constant out of 10 . Therefore, the rangecondition score would be $100 \times 10=1000$. The range condition was broadly interpreted as follows: excellent when the rangecondition index was $>80 \%$, good when $60-80 \%$, moderate to poor when $40-59 \%$, and extremely poor when $<40 \%$.

\section{Assessment of Browse Condition}

The standing browse included all the leaves, twigs, bark, flowers, and fruit that may be eaten by browsers, provided it was within feeding reach of a given type of browser. The height up to which the standing browse was calculated depended on the types of browser species. The sanctuary was too small to keep elephants (Loxodonta africana) and too steep for giraffes (Giraffa camelopardalis). Therefore the browse height was restricted to $2.0 \mathrm{~m}$, since browse above this height is not available to other large browsers. We used BECVOL technique of Smit (1996) to determine the standing browse in each HVU. This method was based on the relationship between the spatial volume of a tree and its actual leaf mass. We surveyed two transects, each $2.5 \mathrm{~m} \times 100 \mathrm{~m}$ in each HVU and identified all the woody plants and recorded their maximum canopy diameter in two directions perpendicular to each other on a horizontal plane, height, height above the ground of the maximum canopy diameter, height and diameter of the lowest leaf material, and base stem diameter just above the basal swelling (Fig. 3).

\section{Data Analysis}

The base information we used was 1) the surface area (ha) covered by each HVU in the TWS, 2) the range condition index of each HVU, 3) the percentage of canopy cover of the grass layer for each HVU (because the ecological grazing capacity in a savannah is influenced by its degree of openness based on the known relationship between grass production and tree density; Richter et al. 2001), 4) a fire factor for each plant community (0.8-1.0, with 0.8 indicating recent fire and 1.0 indicating no recent fire), 5) the annual rainfall (in $\mathrm{mm}$ ), and 6) a topography index of accessibility (0.1-1.0, with $0.1=$ inaccessible and $1.0=$ all of the terrain accessible to plains wildlife). We excluded unsuitable surface areas such as steep slopes and large bodies of water from the calculations for each plant community.

Determination of Ecological Grazing Capacity. To determine the GU as an index of the capacity of a plant community to support wild grazing herbivores in TWS, we used the following equation that was based on plant ecological work by Danckwertz (1989a, 1989b); Smit (1996); Dekker (1997); and Van Rooyen (2002a, 2002b):

$$
\mathrm{GU} \cdot 100 \mathrm{ha}^{-1}=0.547\left[(\mathrm{c}+(\mathrm{r}-\mathrm{R}) 0.23) \mathrm{af}\left(\log _{10} \mathrm{~g}-1\right)^{-0.4}\right]
$$
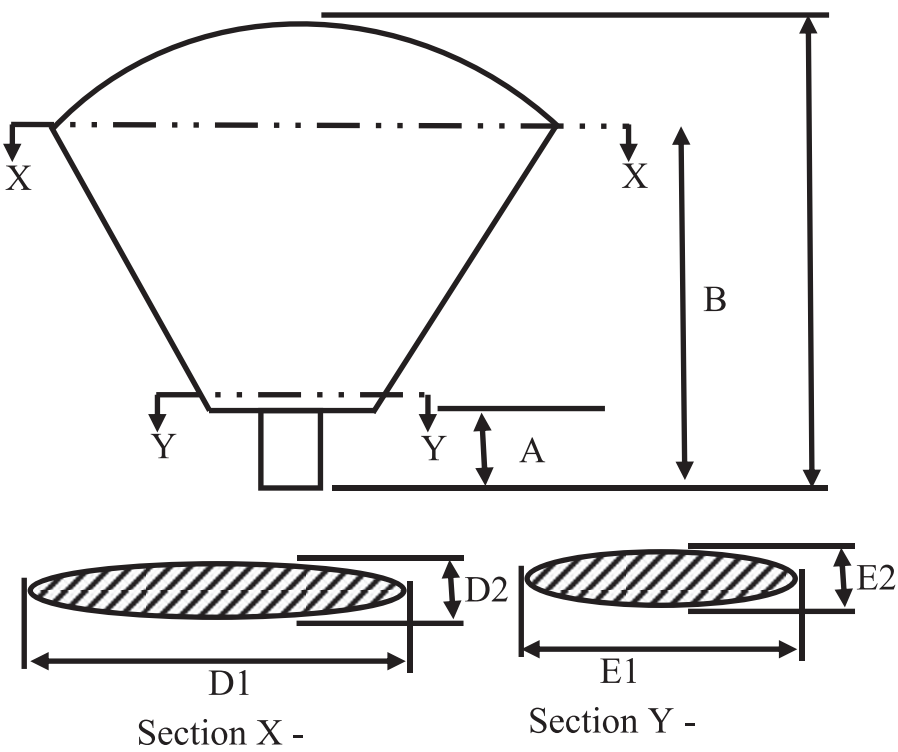

Figure 3. Schematic diagrams for the biomass estimates from canopy volume model inputs (Smit 1996) used in determining browse availability in Tindress Wildlife Sanctuary in September 2007. Input variables included the following:A, tree height; $B$, tree height at maximum canopy diameter; $C$, tree height at minimum canopy diameter; $D$, maximum canopy diameter at height $B$ section $X-X(D 1+D 2)$; and $E$, base canopy diameter at height $C$ section $Y-Y(E 1+E 2)$

where $\mathrm{c}=$ range condition index; $\mathrm{r}=$ mean annual rainfall $(\mathrm{mm})$ over the past $2 \mathrm{yr}$ at the TWS; $\mathrm{R}=1224$ as mean annual rainfall $(\mathrm{mm})$ for TWS over the past 10 or more years; $a=$ topography index of accessibility, the degree of accessibility of the habitat to plains wildlife on a scale of 0.1 to 1.0 , with 1.0 as fully accessible; $\mathrm{f}=$ fire factor on a scale of 0.8 to 1.0 , with 0.8 as recent fire and 1.0 as the absence of fire; andg $=$ percentage of grass cover.

This equation (Equation 1) incorporated range condition, difference between the mean $(r)$ recent annual rainfall for the sanctuary measured over the previous $2 \mathrm{yr}$ and the long-term annual rainfall of TWS (R) represented by average rainfall in the previous 10 or more years, a topography index of habitat accessibility, the influence of fire on plant production, and the percentage of grass cover.

Determination of Ecological Browsing Capacity. To determine the capacity of each HVU to support wild browsing herbivores, we calculated the amount of browse that was available to the browsers in each plant community. The data analysis was done with the BECVOL computer program (Smit 1996); although other approaches such as that of Melville et al. (1999) could also be used. In this study, we calculated the leaf volume for each woody plant at the specific height of the vegetation that could be consumed by the wild herbivores present and expressed in tree equivalents (TE) per hectare $\left(\mathrm{TE} \cdot \mathrm{ha}^{-1}\right)$.

Browsers in Africa are seldom able to actually use $>10 \%$ of the standing plant biomass in any area (Owen and Wiegert 1967; Von Holdt 1999). In fact, feeding studies that have been done in various regions of Africa indicate that this percentage often was $<10 \%$. Studies in the southern Kalahari region (Kruger 1994) and the Kwa Zulu-Natal province of South 
Table 1. Tindress Wildlife Sanctuary range condition index and ecological grazing capacity. Values are in grazing units (GU), based on the vegetation condition in September 2007.

\begin{tabular}{|c|c|c|c|c|}
\hline Characteristics of plant communities ${ }^{1}$ & HVU 1 & HVU 2 & HVU 3 & Entire sanctuary \\
\hline Size (ha) & 50.37 & 23.88 & 238.24 & 312.49 \\
\hline Tree cover (\%) & 6 & 15 & 5 & - \\
\hline Shrub cover (\%) & 15 & 26 & 38 & - \\
\hline \multicolumn{5}{|l|}{ Contribution of ecological classes $(\%)^{2}$} \\
\hline Class 1 & 42 & 2 & 0 & - \\
\hline Class 2 & 27 & 57 & 4 & - \\
\hline Class 3 & 8 & 26 & 11 & - \\
\hline Class 4 & 9 & 9 & 43 & - \\
\hline Class 5 & 6 & 4 & 42 & - \\
\hline Bare soil & 8 & 2 & 0 & - \\
\hline Range condition score (maximum 1000) & 691.00 & 589.00 & 297.00 & - \\
\hline Range condition index (\%) & 69.10 & 58.90 & 29.70 & - \\
\hline Grass cover (\%) & 65.00 & 45.00 & 60.00 & - \\
\hline Mean rainfall $\left(\mathrm{mm} \cdot \mathrm{yr}^{-1}\right)$ & 1333.25 & 1333.25 & 1333.25 & - \\
\hline Topography index of accessibility ${ }^{3}$ & 0.70 & 0.60 & 0.90 & - \\
\hline Fire factor ${ }^{4}$ & 0.80 & 0.80 & 1.00 & - \\
\hline \multicolumn{5}{|l|}{ Ecological grazing capacity at mean annual rainfall: } \\
\hline $\mathrm{GU} \cdot 100 \mathrm{ha}^{-1}$ & 45.70 & 33.63 & 54.62 & - \\
\hline Total GU & 23.02 & 8.03 & 130.14 & 161.19 \\
\hline Mean ecological grazing capacity (GU $\cdot 100$ ha $^{-1}$ ) & - & - & - & 53.73 \\
\hline
\end{tabular}

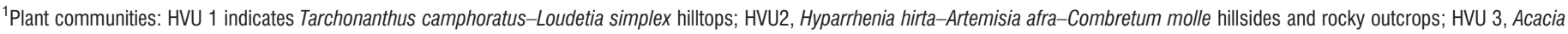
abyssinica-Lippia javanica-Hyparrhenia filipendula riverinevalley bottom.

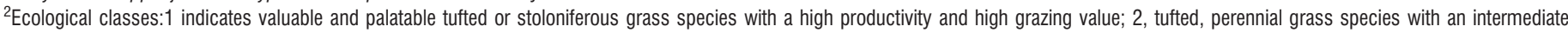
productivity and moderate grazing value; 3 , tufted, tall, perennial grass species with a high productivity but a low grazing value; 4 , generally unpalatable annual and perennial tufted or stoloniferous grass species with an intermediate productivity and a low grazing value; 5 , unpalatable annual grass and forb species with an intermediate productivity and low grazing value.

${ }^{3}$ Topography index of accessibility: 0.1 indicates inaccessible to plains wildlife; 1.0 , fully accessible to plains wildlife.

${ }^{4}$ Fire factor: 0.8 indicates recent fires; 1.0 , no recent fires.

Africa (Emslie and Adcock 1994) and in the central Kenyan highlands (Von Holdt 1999) have all revealed that the browsing capacity should be calculated by using $<10 \%$ of the standing browse. In this study, we used $2.5 \%$ of the standing browse since the bushes were very thick. A greater kudu weighs $140 \mathrm{~kg}$ and would require an estimated 30000 browse-tree equivalents per year for its sustenance. This was taken as equivalent to 1 BU. The ecological browsing capacity was obtained by dividing the available tree equivalent value by 30000 because that is the amount of browse that was required by $1 \mathrm{BU} \cdot \mathrm{yr}^{-1}$ (Botha 1999).

Apportioning Animal Units among the Large Wild Herbivores We calculated the total GUs and BUs and apportioned them among the various wild large herbivores considered suitable for the habitats occurring in TWS. Most of these herbivores were mixed feeders. Therefore, to set stocking densities for each type of herbivore, the percentage of grazing and browsing in its diet was calculated and the GU and BU equivalents based on the relevant diets evaluated. The calculated conversion factor for each type of wildlife to convert to a GU.animal ${ }^{-1}$ and $\mathrm{BU} \cdot$ animal $^{-1}$ was based on the relative metabolic (body) mass of each type of animal (Meissner 1982; Van Rooyen 2002a, $2002 \mathrm{~b}$ ). For example, if a stocking density of 137 Burchell's zebras (Equus burchelli) with a diet of $93 \%$ grass was recommended, the grazing component of these 137 zebras would convert to $13793 \%=127.4$ grazing animals of the size of a Burchell's zebra. The conversion factor for grazers, taking a Burchell's zebra as an example, was calculated as follows:

Burchell's zebra $=\frac{(\text { mean mass of a Burchell's zebra in } \mathrm{kg})^{0.75}}{(\text { mean mass of } 1 \mathrm{GU} \text { in } \mathrm{kg})^{0.75}}$

For the Burchell's zebra the GU per animal was $260^{0.75}$ / $180^{0.75}=1.32 \mathrm{GU} \cdot$ animal $^{-1}$ (Equation 2). Consequently, 127.4 animals of the size of a Burchell's zebra were equivalent to $127.4 \times 1.32 \mathrm{GU}=168$ blue wildebeests.

The browsing component in the diet of a Burchell's zebra was calculated in a similar way. For example, the diet of a Burchell's zebra contains $7 \%$ browse. Therefore, the recommended 137 Burchell's zebras were equivalent to $137 \times 7 \%=9.6$ browsing animals of the size of a Burchell's zebra. The conversion factor for browsers, taking a Burchell's zebra as an example, was calculated as follows:

Burchell's zebra $=\frac{(\text { mean mass of a Burchell's zebra in } \mathrm{kg})^{0.75}}{(\text { mean mass of } 1 \mathrm{BU} \text { in } \mathrm{kg})^{0.75}}$

Therefore, for the Burchell's zebra the BU/animal was $260^{0.75} / 140^{0.75}=1.59 \mathrm{BU} \cdot$ animal $^{-1}$ (Equation 3). Therefore, 
Table 2. Recommended wildlife stocking levels for Tindress Wildlife Sanctuary in Kenya based on the available herbivore grazing units (GU) and browsing units (BU) and vegetation condition in September 2007.

\begin{tabular}{|c|c|c|c|c|c|c|c|c|c|c|}
\hline Type of wildlife & $N^{1}$ & Gd (\%) & $\mathrm{Mm}(\mathrm{kg})$ & No. of $\mathrm{GA}$ & $\mathrm{GU} \cdot \mathrm{A}^{-1}$ & No. of GU & $\mathrm{Bd}(\%)$ & No. of $B A$ & $B U \cdot A^{-1}$ & No. of $\mathrm{BU}$ \\
\hline \multicolumn{11}{|l|}{ Low-selective grazers } \\
\hline Coke's hartebeest (Alcelaphus buselaphus) & 23 & 95 & 130 & 21.85 & 0.78 & 17.118 & 5 & 1.15 & 0.95 & 1.09 \\
\hline Burchell's zebra (Equus burchellii) & 40 & 93 & 260 & 37.2 & 1.32 & 49.014 & 7 & 2.8 & 1.59 & 4.45 \\
\hline Ostrich (Struthio camelus) & 30 & 75 & 69 & 22.5 & 0.49 & 10.961 & 25 & 7.5 & 0.59 & 4.41 \\
\hline$\%$ of total GU and BU & - & - & - & - & - & $29.85 \%$ & - & - & - & $0.47 \%$ \\
\hline \multicolumn{11}{|l|}{ High-selective grazers } \\
\hline Blue wildebeest (Connochaetes taurinus) & 20 & 80 & 180 & 16 & 1.00 & 16 & 20 & 4 & 1.21 & 4.83 \\
\hline Thomson's gazelle (Gazella thomsonii) & 50 & 80 & 23 & 40 & 0.21 & 8.5487 & 20 & 10 & 0.26 & 2.58 \\
\hline$\%$ of total GU and BU & - & - & - & - & - & $9.50 \%$ & - & - & - & $0.35 \%$ \\
\hline \multicolumn{11}{|l|}{ Mixed feeders } \\
\hline Eland (Taurotragus oryx) & 40 & 28 & 460 & 11.2 & 2.02 & 22.638 & 72 & 28.8 & 2.44 & 70.29 \\
\hline Grant's gazelles (Gazella granti) & 55 & 40 & 60 & 22 & 0.44 & 9.6512 & 60 & 33 & 0.53 & 17.48 \\
\hline Impala (Aepyceros melampus) & 50 & 50 & 41 & 25 & 0.33 & 8.2428 & 50 & 25 & 0.40 & 9.95 \\
\hline Warthog (Phacochoerus africanus) & 40 & 65 & 30 & 26 & 0.26 & 6.782 & 35 & 14 & 0.31 & 4.41 \\
\hline$\%$ of total GU and BU & - & - & - & - & - & $18.32 \%$ & - & - & - & $4.80 \%$ \\
\hline \multicolumn{11}{|l|}{ Browsers } \\
\hline Bushbuck (Tragelaphus scriptus) & 50 & 10 & 30 & 5 & 0.26 & 1.3042 & 90 & 45 & 0.31 & 14.17 \\
\hline Grey duiker (Sylvicapra grimmia) & 40 & 12 & 19 & 4.8 & 0.19 & 0.8889 & 88 & 35.2 & 0.22 & 7.87 \\
\hline Klipspringer (Oreotragus oreotragus) & 80 & 20 & 13 & 16 & 0.14 & 2.2291 & 80 & 64 & 0.17 & 10.77 \\
\hline Greater kudu (Tragelaphus strepsiceros) & 55 & 15 & 140 & 8.25 & 0.83 & 6.8328 & 85 & 46.75 & 1.00 & 46.75 \\
\hline$\%$ of total GU and BU & - & - & - & - & - & $4.36 \%$ & - & - & - & $3.74 \%$ \\
\hline All herbivores & 478 & - & - & - & - & 160.21 & - & - & - & 199.05 \\
\hline Total available & - & - & - & - & - & 161.19 & - & - & - & $1,068.97$ \\
\hline Balance available & - & - & - & - & - & 1 & - & - & - & 870 \\
\hline Total \% GU and \% BU & - & - & - & - & - & $99.40 \%$ & - & - & - & $18.62 \%$ \\
\hline
\end{tabular}

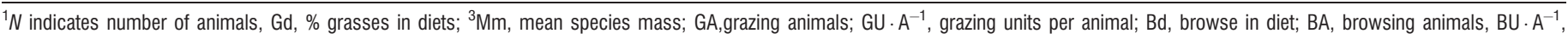
browsing units per animal species.

9.6 animals of the size of a Burchell's zebra were equivalent to $9.6 \times 1.59 \mathrm{BU}=15$ greater kudus.

\section{RESULTS}

\section{Resource Mapping}

We identified and described three HVUs (Table 1): 1) Tarchonanthus camphoratus-Loudetia simplex hilltops (50.37 ha), 2) Hyparrhenia hirta-Artemisia afra-hillsides and rocky outcrops (23.88 ha), and 3) Acacia abyssinica-Lippia javanicaHyparrhenia filipendula riverine/valley bottom (238.24 ha). The range-condition index of each of these HVUs varied from $69.1 \%$ in the hilltops to $29.7 \%$ in the riverine/valley bottoms, indicating that the hilltops were in good range condition, while the Riverine/Valley Bottoms were in poor condition (Table 1).

\section{Designed Ecological Grazing Capacity}

For each community the ecological grazing capacity was calculated as $\mathrm{GU} \cdot 100 \mathrm{ha}^{-1}$. For example, the range condition index of $69.1 \%$ for hilltops indicated a range in a good condition. This community had a grass cover of $65 \%$, had a high degree of accessibility to the herbivores, had experienced a recent fire event, and had a mean annual rainfall of 1333 $\mathrm{mm} \cdot \mathrm{yr}^{-1}$. Its ecological grazing capacity was $45.7 \mathrm{GU} \cdot 100$ $\mathrm{ha}^{-1}$. Consequently, the 50.37 ha covered by this plant community could support $0.504 \times 45.7=23.03$ GU. The entire ranch could support 169.19 GU (Table 1), giving a mean ecological grazing capacity of $53.73 \mathrm{GU} \cdot 100 \mathrm{ha}^{-1}$.

\section{Designed Ecological Browsing Capacity}

The standing available browse was $16014 \mathrm{TE} \cdot \mathrm{ha}^{-1}$ in the hilltops HVU, $73112 \mathrm{TE} \cdot \mathrm{ha}^{-1}$ in the hillside HVU, and $104058 \mathrm{TE} \cdot \mathrm{ha}^{-1}$ in the riverine/valley bottom HVU up to a height of $2 \mathrm{~m}$. A kudu weighing $140 \mathrm{~kg}$ and requiring 30000 browse tree equivalent per year is equal to $1 \mathrm{BU} \cdot \mathrm{yr}^{-1}$. Hence dividing the TE in each HVU by the 30000 and multiplying the results by the HVU's area gave the total of $1519 \mathrm{BU}$. The ecological browsing capacity of the Sanctuary was therefore $342.09 \mathrm{BU} \cdot 100 \mathrm{ha}^{-1}$.

\section{Wild Herbivore's Dietary Differences and Stocking Densities}

Due to the relatively poor grass cover in forested areas found at TWS, a ratio of $<10 \%$ low-selective and high-selective grazers combined, $40 \%$ mixed feeders, and $>50 \%$ browsers was recommended for the composition of the BU (Table 2). This was because TWS was more suited to mixed feeders and browsers. For wildlife ranching the economic grazing and browsing capacity for an area are usually set at $70-80 \%$ of the ecological grazing and browsing capacity. 


\section{DISCUSSION}

The UM model used in this study has been extensively used in South Africa (Peel et al. 1994; Van Rooyen et al. 1994; Smit 1996; Dekker 1997; Van Rooyen 2002a; Bothma et al. 2006). Similar livestock substitution ratio models were used in estimating livestock carrying capacities in Australia (Johnston and Garrad 1999), and in the United States (Holechek 1988) where dry sheep equivalents were used as standard units to estimate livestock stocking levels. Although their approach is more objective than the FIMs, they are limited in that they focus only on grazing livestock of extremely low species diversity. Bothma et al. (2006) expanded this approach by separating the grazing and browsing dietary components and apportioning the various wildlife species based on their foraging patterns. The stocking densities calculated using these approaches was more logical and objective and the diversity in the vegetation resources was used optimally.

The recommended stocking density of $160.21 \mathrm{GU}$ and 199.05 BU for the ranch is only an approximation, and the current rainfall, range condition, and physical condition of the animals must be monitored to make final adjustments through active adaptive management. This should be repeated every year. TWS is a rather small area that is completely enclosed. A static model to determine stocking density is more accurate in large, open environments where wildlife can move around freely to exploit localized patches of herbage production opportunistically. On smaller, enclosed wildlife ranches and nature reserves, this approach becomes impracticable. Consequently, the stocking densities must be adaptable and based on the quantity and quality of plant food resources available in a given place at a given time. Therefore stocking levels should be set at $70-80 \%$ of the calculated total potential (Table 2) to allow for optimal utilization of favorable conditions and avoidance of hazards such as drought mortalities during unfavorable conditions. In such a way, a management program could be developed for sustainable use of the renewable natural resources. Naturally, it would require regular monitoring of rainfall, fire, and vegetation resources.

We deliberately used only $18.6 \%$ of the available BU since TWS is a water catchment area for human use and its better understocked to avoid erosion. The final choice of the types of wildlife also can be varied depending on the preferences and objectives of the TWS. Any overstocking detected in future on the sanctuary can be rectified by harvesting wildlife selectively without disturbing the ratio of the different feeding classes. Water supply is a major constraint in the hilltops HVU; TWS should improve water supply in this area for wildlife use.

\section{MANAGEMENT IMPLICATIONS}

Currently, a key challenge to wildlife conservation in Kenya is the rapid conversion of marginal wildlife habitat lands to human settlement (Akama 1998). The displaced wildlife eventually dies, moves, or is moved to other conservation systems. The process of designing and designating a wildlife conservancy requires licensing from Kenya Wildlife Services. Among the prerequisites for licensing is a management plan that clearly shows the types and number of wildlife species a specific area is able to hold. This study has applied guidelines used elsewhere (Holechek 1988; Peel et al. 1994; Dekker 1997; Scarnecchia 1990; Bothma et al. 2006) to a Kenyan study and can be used to determine the species types and numbers a conservancy can stock. The vegetation composition will determine the types of animal species a conservancy can keep, based on their feeding strategies. The available GUs and BUs and the rainfall regimes will determine the number of animals that can be stocked. This procedure allows for adaptive management as more knowledge about a specific conservancy becomes available with time (Bothma et al. 2004, 2006). This procedure is also very useful in places were consumptive wildlife utilization is allowed. A farmer, rancher, or wildlife conservator will even be able to project the return on investments the wildlife resource is likely to yield. Therefore, validating these methods and making them available to wider range of users is very useful in the management of wildlife in Kenya.

\section{ACKNOWLEDGMENTS}

We wish to acknowledge Mr Robert Nesta, Ms Fiona Nelima, and Dr Charles Musyoki for reviewing various drafts of this paper. We sincerely thank them all.

\section{LITERATURE CITED}

AкамA, J. S. 1998. The evolution of wildlife conservation policies in Kenya. Journal of Third World Studies 15:103-117.

Вотна, J. 0. 1999. A resource management plan for the Lewa Wildlife Conservancy in the Meru District of the central Kenyan highlands [dissertation]. Pretoria, South Africa: Centre for Wildlife Management, University of Pretoria. $282 \mathrm{p}$.

BотнмA, J. Du P. 2002. Game ranch management. 4th ed. Pretoria, South Africa: Van Schaik. 459 p.

Bothma, J. du. P., N. Van Rooyen, and M. W. Van Rooyen. 2004. Using diet and plant resources to set wildlife stocking densities in African savannas. The Wildlife Society Bulletin 32:840-851.

Bothma, J. Du P., N. Van Rooyen, and M. W. Van Rooven. 2006. Using diet and plant resources to set wildlife stocking densities in African savannas. The Wildlife Society Bulletin 32-34:840-851.

DanckwerTz, J. E. 1989a. Animal performance. In: J. E. Danckwertz and W. R. Teague [EDS.]. Veld management in the Eastern Cape. Pretoria, South Africa: Department of Agriculture and Water Supply, Government Printer. p. 47-60.

DANCKWERTZ, J. E. 1989b. Management of veld types. In: J. E. Danckwertz and W. R. Teague [EDS.]. Veld management in the Eastern Cape. Pretoria, South Africa: Department of Agriculture and Water Supply, Government Printer. p. 140-149.

DEkKER, B. 1997. Calculating stocking rates for game ranches: substitution ratios for use in the Mopani veld. African Journal of Range and Forage Science 14:62-67.

Delany, M. J., and D. C. D. Happold. 1979. Ecology of African land mammals. London, UK: Longman. $704 \mathrm{p}$.

Dhondt, A. A. 1989. Carrying capacity: a confusing concept. Acta Gecologia, Gecologica Generalis. 9:337-346.

Emslie, R. H., And K. Adcock. 1994. Feeding ecology of black rhinoceros. In: B. L. Penzhorn and N. P. J. Kriek [EDS.]. Rhinos as game ranch animals. Onderstepoort, South Africa: The Wildlife Group, South African Veterinary Association. p. 65-81.

Georgiadis, N., M. HaCK, and K. TuRPIN. 2003. The influence of rainfall on zebra population dynamics: implications for management. Journal of Applied Ecology 40:125-136. 
Holechek, J. L. 1983. Considerations concerning grazing systems. Rangelands 5:208-211.

HoLECHEK, J. L. 1988. An approach for setting the stocking rate. Rangelands 10:1014.

Holechek, J. L., R. D. Pieper, and C. H. Herbel. 1989. Range management. Englewood Cliffs, NJ, USA: Prentice-Hall, Inc. 587 p.

Jambiya, G., S. A. H. Mllledge, and N. Mtango. 2007. 'Night time spinach': conservation and livelihood implications of wild meat use in refugee situations in north-western Tanzania. Dar es Salaam, Tanzania: TRAFFIC East/Southern Africa. $60 \mathrm{p}$.

Johnston, P. W., and S. W. GarRad. 1999. Estimating livestock carrying capacities in south-west Queensland, Australia. In: Proceedings of the International Rangeland Congress; 19-23 July 1999; Townsville, QLD, Australia. Townsville, QLD, Australia: Congress Organizing Committee. Volume 2. p. 861-863.

Kamweya, A. M., S. M. Ngene, And S. M. MuYa. 2012. Occurrence and level of elephant damage to farms adjacent to Mount Kenya forests: implications for conservation. Journal of Biology, Agriculture and Healthcare 2:41-54.

Kent, M., AND P. Coker. 1995. Vegetation description and analysis. New York, NY, USA: John Wiley and Sons. $405 \mathrm{p}$.

Kruger, J. W. 1994. The feeding ecology and behaviour of reintroduced giraffe (Giraffa camelopardalis) in the Kalahari Gemsbok National Park [MSc dissertation]. Pretoria, South Africa: University of Pretoria. 175 p.

[KSS] KenYA Soll SURVEY. 1982. Exploratory soil map and agro-climatic zone map of Kenya, 1980: scale 1:1,000,000. In: W. G. Sombroek, H. M. H. Braun, and B. J. A. Van der Pouw [EDs.]. Kenya soil map. National Agricultural Laboratories. Nairobi, Kenya: Kenya Soil Survey. 55 p.

MEgATAB: A Visual Editor for Sociological Tables [computer program]. 1996. Giessen, Germany: Ulft.

Melville, H. I., A. S. Cauldwell, and J. Du R. Bothma. 1999. A comparison of two techniques for estimating tree canopy volume. South African Journal of Wildlife Research 29:1-5.

MentIs, M. 1981. An evaluation of the wheel-point and step-point methods of veld condition assessments. Proceedings of the Grassland Society of Southern Africa 16:89-94.

NgunsIRI, P. 1997. Environment-Kenya: making wildlife pay. Available at: http:// www.ips.fi/koulut/199751/12.htm. Accessed 13 June 2013.

Owen, D. F., and R. G. Wiegert. 1967. Do consumers maximise plant fitness? Oikos 27:488-492.

Peel, M. J., C. Pauw, and D. D. Snyman. 1994. The concept of grazer and browser animal units for African savannah areas. Bulletin of the Grassland Society of Southern Africa 5:61.
Pratt, D. J., J. R. Blackie, and M. D. Gwynne. 1977. Rangeland management and ecology in East Africa. London, UK: Hodder and Stoughton Publishers. $310 \mathrm{p}$.

Richter, C. G., F. H. A. Snyman, And G. N. Smit. 2001. The influence of tree density on the grass layer of three semi-arid savannah types in southern Africa. African Journal of Range and Forage Science 18:103-109.

SCARNECCHIA, D. L. 1990 Concepts of carrying capacity and substitution ratios: a systems viewpoint. Journal of Range Management 43:553-555.

SMIT, G. N. 1996. BECVOL: biomass estimates from canopy volume (version 2)user's guide. Bloemfontein, South Africa: University of the Free State. $33 \mathrm{p}$.

Society for Range Management. 1989. A glossary of terms used in range management. Denver, CO, USA: Society for Range Management. $20 \mathrm{p}$.

TalNTON, N. M. [ED.]. 1999. Veld management in South Africa. Pietermaritzburg, South Africa: University of Natal Press. $472 \mathrm{p}$.

tURBOVeg: Software Package for Input, Processing and Presentation of PhytosociologICAL DATA [computer program]. 1996. Lancaster, UK: University of Lancaster.

Van Oudtshoorn, F. 1999. Guide to grasses of southern Africa. Pretoria, South Africa: Briza. $288 \mathrm{p}$

Van Rooyen, N. 2002a. Veld management in the savannas. In: J. du P. Bothma [ed.]. Game ranch management. 4th edition. Pretoria, South Africa: Van Schaik. $p$. 571-617.

VAN Rooyen, N. 2002b. Veld condition assessment and stocking a game ranch. In: B. L. Penzhorn [ED.]. Proceedings of a Symposium on Game Ranch Planning and Management; 1-2 November 2002; Onderstepoort, South Africa. Onderstepoort, South Africa: The Wildlife Group, South African Veterinary Association. p. 41-51.

Van Rooyen, N., G. J. Bredenkamp, 0. K. Theron, J. du P. Bothma, and E. A. N. Le Riche. 1994. Vegetational gradients around artificial watering points in the Kalahari Gemsbok National Park. Journal of Arid Environments 26:349-361.

Von HoLdt, A. L. 1999. Ecological separation by browsers on the Lewa Wildlife Conservancy, Kenya [MSc dissertation]. Pretoria, South Africa: University of Pretoria. $194 \mathrm{p}$.

VoRSTER, M. 1982. The development of the ecological index method for assessing range condition in the Karoo. Proceedings of the Grassland Society of Southern Africa 17:84-89.

Watson, R., K. H. Fitzgerald, and N. Gitah. 2010. Expanding options for habitat conservation outside protected areas in Kenya: the use of environmental easements. African Wildlife Foundation Technical Papers Number 2. Available at: http://www.awf.org/sites/default/files/media/Resources/Books\%20and\%20Papers/ AWF Env_Easement_Technical Paper_2 March_2010.pdf. Accessed 13 June 2013. 